\section{Domestic mercury pollution}

SIR-Mills in his recent Scientific Correspondence' identified a previously unsuspected source of atmospheric mercury and speculated on its toxicity. Here, I report another novel source of mercury pollution in predominantly domestic settings, where it has hitherto been thought a rarity $^{2}$. I believe this is the first mention of widespread domestic exposure to mercury vapour.

Mercury metal is used in Latin American and Caribbean communities for occult purposes. It is sold in shops called botanicas which stock medicinal plants, magical medicines, incense, candles and perfumes ${ }^{3}$. These and other religious articles are dispensed to adherents of syncretistic Afro-Caribbean/Latin American religions, such as Santeria and Voodoo, as well as to the general public.

In a survey of 115 botanicas in 13 cities with large Hispanic populations in the United States and Puerto Rico, 99 were found to sell mercury. A brief survey of botanicas in Mexico, Colombia and the Dominican Republic revealed that they too dispense mercury.

Botanicas typically dispense mercury in gelatin capsules, or occasionally glass vials. Of 41 samples purchased, the median amount dispensed was $8.5 \mathrm{~g}$, with a mean of $9.0 \mathrm{~g}$, a range of 1.5 to $31.3 \mathrm{~g}$ and a modal cost of $\$ 1.00$. Of 28 botanicas visited in New York City, 13 prescribed that mercury be sprinkled on the floor or mixed with soap and water used to mop the floor, to rid the house of evil influences or for other purposes. Some botanicas suggested repeated application at intervals of three days to a week, until the desired result is attained. One shopkeeper recommended placing mercury in an open container with a magnet. Any of these procedures would liberate mercury vapour directly into the room's atmosphere.

Several shopkeepers recommended that mercury should be carried on the person, kept in containers in the house, placed in bath water, or mixed with perfume, soap solutions or ammonia and camphor. Others prescribed placing mercury in devotional candles.

Mercury also presents an occupational hazard. My colleague twice observed shopkeepers spill mercury without removing or chemically neutralizing it. One proprietress said that she intentionally scattered mercury about her botanica to "bring good things", as well as adding a bit to each prescription she dispensed.

It is evident that the concentration of mercury vapour in room air will vary widely, depending on such factors as quantity dispensed, amount used, frequency of application, type of floor surface, air temperature, volume of room, height above floor level and ventilation. It is equally apparent that the proposed $1 \mu \mathrm{g} \mathrm{m}^{-3}$ "upper limit for long-term exposure to mercury vapour in the air" cited by Mills ${ }^{1}$ could easily be exceeded by repeated applications in a small apartment.

The most likely victims of these practices are young children, exposed to the highest levels of vapour as they sleep, crawl and play on contaminated floors ${ }^{+.5}$. Mercury vapour enters the fetus via the placenta, and the infant via breast milk ${ }^{6}$. One result of mercury vapour's neurotoxicity on penetrating the blood-brain barrier $^{7}$ is the subtle personality change called erethism. It seems likely that children are the principal victims of mercurial erethism, which is characterized by hostility, withdrawal, tendency to resent being observed, quick temper, loss of self confidence and loss of memory ${ }^{5.6}$. Sunderman's advice ${ }^{8}$ of "giving careful consideration to intoxication from undetected exposure to mercury... in patients

\section{More ellipses}

SIR-Klaczko and Bitner-Mathe in their Scientific Correspondence' reported that a large portion of the wing outlines of several species of Drosophila could be described as elliptical arcs and hence by only two parameters. But the fit can be improved by two methods, both using Fourier analysis, which would allow more information to be extracted than the length to width ratio of the ellipse.

In the first method $^{2}$, the radius function (the distance of the perimeter from an arbitrary central point as a function of the angle subtended from a chosen axis) is decomposed to a set of harmonics using Fourier analysis. The arc can then be described as precisely as is required by a set of $2 n$ coefficients, where $n$ is the number of harmonics. Unfortunately, this simple method gives different results depending on the selection of the central point and axis, so it is of limited value in comparing shapes with few homologous points of reference.

The second method ${ }^{3}$ uses two axes and the coefficients are independent of the size, position and orientation of the object. The arc is first smoothed by replacing it by short line segments pointing at either $0,45,90, \ldots$ or 315 degrees to a chosen axis. A Fourier series can then be found describing the $X$ and $Y$ projections of a point on this new arc to any required accuracy.

If one or more coefficients is set to zero then primitive shapes are obtained, of which the simplest are ellipses. Each harmonic in the Fourier series can be represented as a phasor, each of which has an elliptical locus, and the sum of the loci is an epicyclic path which approximates encountering depressions, behavioural and neurological disorders", is worth heeding, particularly in the evaluation of emotionally disturbed children.

There seems ample justification for a programme to measure mercury vapour levels and to test exposed individuals. Sociologial research is also required to develop an effective health-education programme for botanica owners and their clients.

ARNOLD P. WENDROFF

Occupational Therapy Program,

Columbia University,

630 West 168th Street,

New York, New York 10032, USA

1. Mills, A. Nature 346, 615 (1990).

2. McNeil, N. 1., Olver, R. E., Issler, H. C. \& Wrong, O. M Lancet i, 270 (1984).

Murphy, J. M. Santeria: An African Religion in America. (Beacon, Boston, 1988).

(Beacon, Boston, 1988). Archs dis. Childhood 62, 294 (1987)

5. Hardy, H. L \& Finkel, A. J. Hamilton \& Hardy's Industrial Toxicology 4th edn 101 (Wright, Boston, 1983)

. Battigelli, M. C. in Environmental and Occupational Medicine. (ed. Rom, W. N.) 453 (Little Brown, Boston, 1983).

. Choi, B. H. Progr. Neurobiol. 32, 449 (1989).

8. Sunderman, F. W. Ann. Clin. Lab. Sci. 18, 99 (1988).

the outline. The ellipses can be rotated and scaled into a standard position so that the coefficients depend only on the shape of the outline and not on the orientation in which the object is recorded.

Fourier coefficients are difficult to interpret geometrically because information about a single feature becomes confounded across several harmonics. Nevertheless, the distinctiveness of a feature on the outline will be associated with the eccentricity of certain elliptic loci. A regular partitioning of the outline into $n+1$ arcs should affect the size of the $n$th ellipse. Because there are two series there are $4 n$ coefficients which can be analysed to estimate the similarity of the shape of different outlines such as wings.

Both methods are limited by the accuracy of digitization and number of points in the outline. Errors in the digitization are more likely to affect the higher harmonics. I recorded the valve outlines of freshwater mussels using a Graphtec digitizing pad model KD4030 connected to an IBM personal computer (this could be better done with video camera equipment). I have written Turbo Pascal v4.0 software to save the digitized data,

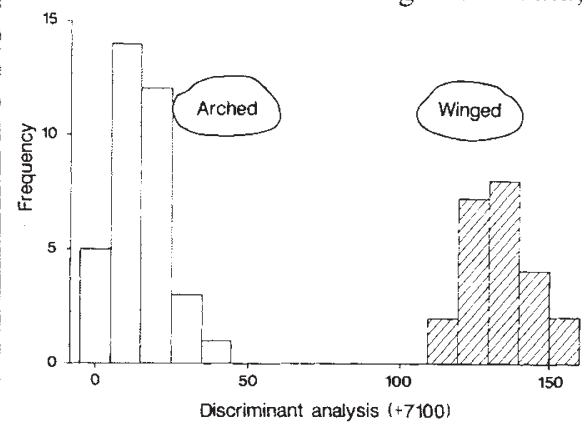

Discriminant analysis for the hyriid mussel A. jacksoni. 